\title{
Dialysis Hypotension: A Role for Inadequate Increase in Arginine Vasopressin Levels? A Systematic Literature Review and Meta-Analysis
}

\author{
Esmée M. Ettema ${ }^{a}$ Debbie Zittema ${ }^{a}$ Johanna Kuipers ${ }^{b}$ Ron T. Gansevoort ${ }^{a}$ \\ Priya Vart $^{c}$ Paul E. de Jong ${ }^{a}$ Ralf Westerhuis ${ }^{b}$ Casper F.M. Franssen ${ }^{a}$ \\ ${ }^{a}$ Division of Nephrology, Department of Internal Medicine, ${ }^{b}$ Dialysis Center Groningen, and ${ }^{c}$ Department of Health \\ Sciences, University Medical Center Groningen, Groningen, The Netherlands
}

\section{Key Words}

Arginine vasopressin · Hemodialysis · Intradialytic hypotension

\begin{abstract}
Background: Intradialytic hypotension is a common complication of hemodialysis (HD). Some studies have suggested that inadequate arginine vasopressin (AVP) increase could play a role in the pathogenesis of intradialytic hypotension. However, AVP levels during HD and its relation to hypotension has never been systematically studied. Summary: PubMed and Embase were searched (1970-2013, search terms 'vasopressin' and 'hemodialysis') for studies reporting on AVP levels during standard HD or other dialysis techniques. Observational studies reporting on AVP levels preand postdialysis were additionally included in a meta-analysis. Thirty-seven studies were included in the systematic literature review, of which 26 studies were eligible for meta-analysis. The main findings were that pretreatment AVP levels were higher in dialysis patients compared with healthy controls $(6.4 \pm 3.5$ vs. $2.5 \pm 1.3 \mathrm{pg} / \mathrm{ml}, \mathrm{p}=0.003)$ and that plasma AVP levels showed little or no increase during HD (from $7.0 \pm 4.9$ to $8.8 \pm 9.3, p=0.433$ ). Significant heterogeneity was found between studies. Meta-regression analysis revealed no significant associations between AVP and pa-
\end{abstract}

tient or study characteristics. Studies on other dialysis techniques showed mixed results regarding the AVP course. The eight studies that addressed the relation between intradialytic hypotension and AVP also showed inconsistent results. Key Messages: Plasma AVP levels are higher in dialysis patients compared with healthy controls, but show little or no increase during HD. The lack of a rise in AVP levels during HD may be pathophysiologically involved in the onset of intradialytic hypotension, but firm conclusions are not possible from our review of the literature.

(c) 2014 S. Karger AG, Basel

\section{Introduction}

Intradialytic hypotension is a serious complication of hemodialysis (HD) and is estimated to occur in about 20$30 \%$ of HD treatments $[1,2]$. Symptoms of intradialytic hypotension vary from mild, transient symptoms, such as muscle cramps, nausea and dizziness, to serious complications like cardiac ischemia and arrhythmias, and cerebrovascular events [1,3]. Intradialytic hypotension is also associated with an increased mortality [4]. Intradialytic hypotension occurs when cardiovascular compensatory mechanisms are unable to compensate for the decrease in blood volume during HD $[1,5,6]$. Important physiologic

\section{KARGER}

E-Mail karger@karger.com

www.karger.com/ajn
C 2014 S. Karger AG, Basel

0250-8095/14/0392-0100\$39.50/0
Casper F.M. Franssen, MD, PhD

Department of Internal Medicine, Division of Nephrology University Medical Center Groningen, University of Groningen Hanzeplein 1, NL-9713 GZ Groningen (The Netherlands) E-Mail c.f.m.franssen@ umcg.nl 


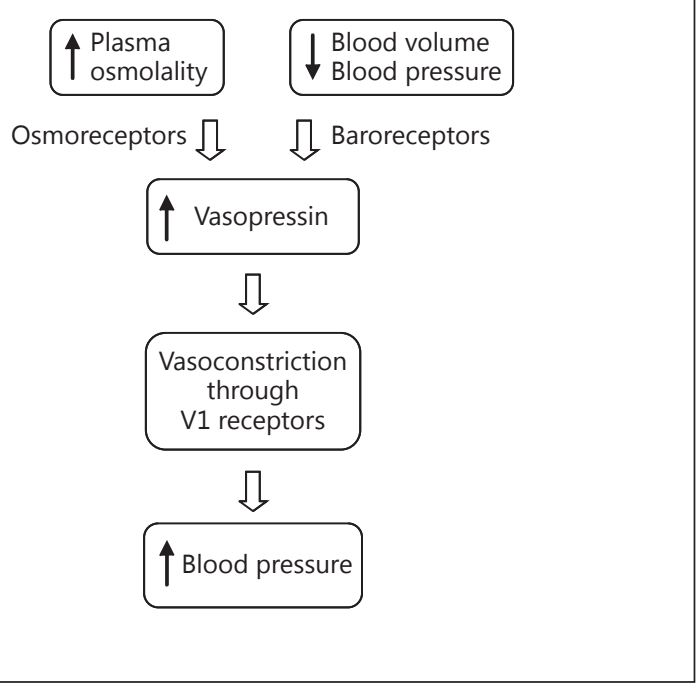

Fig. 1. Major pathways leading to AVP release and a subsequent rise in blood pressure in hemodialysis patients.

compensatory mechanisms for maintaining blood pressure during HD are vascular refill from interstitial tissue, an increase in heart rate and contractility, and arterial and venous vasoconstriction $[1,7]$. These mechanisms are predominantly regulated by the sympathetic nervous system and the renin-angiotensin system. Although dialysis patients generally have an overactive sympathetic nervous system and renin-angiotensin system [8-12], the increase in peripheral resistance is insufficient to prevent intradialytic hypotension in many patients $[13,14]$. As a consequence, the role of the vasoconstrictor arginine vasopressin (AVP) for maintaining blood pressure may become increasingly important [15-17].

\section{Physiology of AVP}

AVP, also known as the antidiuretic hormone, is a $1-\mathrm{kDa}$ nonapeptide, synthesized in the supraoptic and paraventricular nuclei of the hypothalamus and stored in secretory granules in the posterior pituitary gland. The normal plasma AVP concentration in a fasted and hydrated person is below $4 \mathrm{pg} / \mathrm{ml}$ [18-21]. The plasma halflife of AVP is about 5-35 min and it is rapidly metabolized by liver and kidney vasopressinases [19, 20, 22].

The most powerful stimuli for AVP release are hyperosmolality, which acts through the osmoreceptors, and hypotension and hypovolemia, which both act through

Dialysis Hypotension and Vasopressin the baroreceptors, i.e. the baroreceptor reflex (fig. 1) [1820]. Under normal physiological conditions, changes in plasma osmolality are the main regulator of AVP release $[20,23-26]$. In comparison with a rise in plasma osmolality, decreases in plasma volume and blood pressure are less potent stimuli for AVP release, but the magnitude of the potential AVP response to hypovolemia and hypotension exceeds the potential AVP response elicited by an increase in plasma osmolality $[23,26]$.

Importantly, the baroreceptor and osmoreceptor pathways do not function in isolation since a reduction in plasma volume increases the sensitivity of the osmoreceptors [26]. AVP release is also stimulated by nausea and pain via central nervous input $[19,26]$.

AVP exerts its physiological actions by binding to three distinct receptors. Stimulation of V1 receptors causes vasoconstriction of the systemic arteries and venous capacitance vessels [20,27], whereas V2 receptors mediate antidiuretic activity. There are also V3 pituitary receptors, formerly known as V1b receptors, of which the function is less well understood, but appear to be involved in the release of adrenocorticotropic hormone $[18,19]$. V1 receptors are mainly found on vascular smooth muscle of the systemic, renal, splanchnic and coronary circulation $[23,28]$. The degree of vasoconstriction depends on the vascular bed. AVP is a potent vasoconstrictor, especially in skin and skeleton muscle, and to a lesser extent in mesenteric, coronary and cerebral circulations $[19,20,22]$. Thus, besides regulating the body's water balance, AVP has the ability to increase blood pressure through systemic vasoconstriction [19, 20]. The effect of AVP is normally overshadowed by other blood pressure-regulating systems like the sympathetic nervous system and renin-angiotensin system [16, 29]. However, AVP becomes increasingly important in maintaining hemodynamic stability when blood pressure is endangered and/or during hypovolemia $[15,20,22,30$ 33].

\section{Stimuli for AVP Release during HD}

HD with ultrafiltration inevitably leads to reductions in blood volume and blood pressure, both powerful stimuli for AVP release, in the vast majority of patients. Other stimuli for the release of AVP during HD include nausea and pain related to puncture of the fistula. The effect of conventional HD on plasma osmolality is not well delineated, with some studies reporting no change $[29,34]$ and others reporting a decrease in plasma osmo- 
Table 1. Theoretical stimuli for AVP release during dialysis

\begin{tabular}{|c|c|c|c|}
\hline $\begin{array}{l}\text { Stimulus } \\
\text { for AVP release }\end{array}$ & Physiological effect in healthy individuals & Stimulus for AVP release during HD & $\begin{array}{l}\text { Expected effect } \\
\text { on AVP levels } \\
\text { with HD }\end{array}$ \\
\hline $\begin{array}{l}\text { Increase in } \\
\text { osmolality }\end{array}$ & $\begin{array}{l}\text { Osmoregulation is a sensitive system and small } \\
\text { increases in osmolality cause a significant rise in } \\
\text { AVP levels }[20,23]\end{array}$ & $\begin{array}{l}\text { Several studies reported no change }[29,34] \text { or } \\
\text { a decrease }[15,35-44] \text { in plasma osmolality } \\
\text { during HD }\end{array}$ & - \\
\hline Nausea & Nausea stimulates AVP release $[19,21,22,26,75]$ & $\begin{array}{l}\text { One study showed that plasma AVP levels } \\
\text { rose markedly in hypotension-prone patients } \\
\text { experiencing nausea, as opposed to patients } \\
\text { who did not experience nausea [29] }\end{array}$ & + \\
\hline Pain & $\begin{array}{l}\text { Pain acutely stimulates the release of AVP }[19,22 \text {, } \\
26]\end{array}$ & $\begin{array}{l}\text { Puncture of the arteriovenous fistula can be } \\
\text { painful and theoretically stimulates AVP } \\
\text { release }\end{array}$ & + \\
\hline
\end{tabular}

lality [15, 35-44]. Table 1 summarizes the theoretical effects of HD on AVP release. It is clear that the stimuli for AVP release prevail. Therefore, one would theoretically expect a significant rise in AVP levels during HD. It seems, however, that plasma AVP levels show little or no increase during HD and it could, therefore, well be that an inadequate rise of AVP plays an important role in the pathogenesis of intradialytic hypotension $[24,33]$. However, since most studies were small-scale and underpowered, the true effect of HD on AVP levels may be underestimated.

In this systematic literature review, we first summarize the available observational studies on plasma AVP levels in standard HD and other dialysis techniques. Details on study selection, data extraction and statistical analysis are provided in the online supplementary material (item S1; for all online suppl. material, see www. karger.com/doi/10.1159/000358203). We specifically investigated: (1) whether AVP levels before dialysis differ from those in healthy controls, (2) whether standard HD is associated with a change in AVP levels and (3) whether there is a relation between the intradialytic change in AVP levels and intradialytic hypotension. Next, we discuss possible underlying mechanisms for inadequate AVP increase. Finally, we address whether intradialytic hypotension may be prevented by AVP-based interven- tions, such as modification of the HD prescription to stimulate endogenous AVP release and the administration of AVP analogues.

\section{Results of the Systematic Literature Review and Meta-Analysis}

\section{Search Results and Study Characteristics}

Figure 2 shows the flow diagram of our search strategy. One hundred and two studies were identified by the initial search, 66 in PubMed and 36 in Embase. Thirty-one of these articles were duplicate publications and 21 articles were excluded on the basis of screening of the abstract. A total of 50 full-text articles were assessed, of which 13 were excluded since they did not meet the eligibility criteria. Online supplementary item S2 provides an overview of the excluded articles. Thirty-seven articles were included in the systematic review (online suppl. table S1). Of these, 26 studies provided information on plasma AVP levels before and after standard HD (defined as HD with constant ultrafiltration rate and dialysate conductivity) and these studies were included in the metaanalysis of the effect of standard HD on AVP levels. Online supplementary table S2 provides the key features of the studies included in the meta-analysis. 


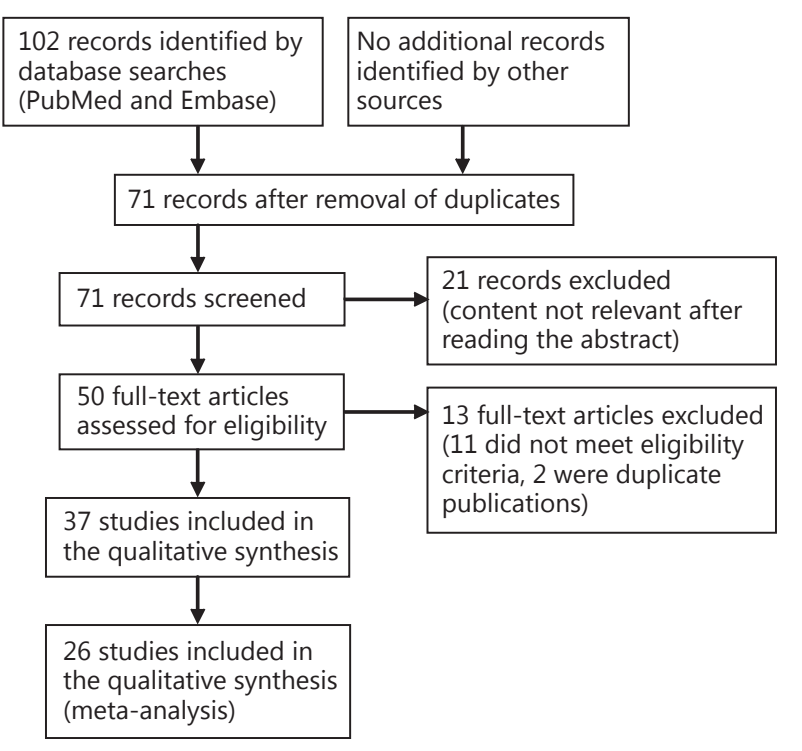

Fig. 2. Search strategy of the systematic literature review.

\section{Plasma Vasopressin Levels in Dialysis Patients and Healthy Individuals}

Plasma AVP levels were measured in both HD patients and healthy controls in a total of 7 studies. Despite considerable variation, the studies in which healthy controls were included [24, 25, 35, 37, 45-47] uniformly showed that pretreatment plasma AVP levels were more than twice as high in dialysis patients compared with healthy controls $(6.4 \pm 3.5$ vs. $2.5 \pm 1.3 \mathrm{pg} / \mathrm{ml}, \mathrm{p}=0.003)$ in an indirect comparison (fig. 3a) as well as in a direct comparison (fig. 3b).

Plasma AVP levels in patients varied widely, with some studies reporting pre-HD plasma AVP levels above the concentration regarded as the upper level of normal of 4 $\mathrm{pg} / \mathrm{ml}[2,16,24,25,35,37-41,45-54]$, while others found pretreatment plasma AVP levels around or below $4 \mathrm{pg} / \mathrm{ml}$ [32-34, 43, 44, 55-57] (fig. 3a).The variation in pretreatment plasma AVP levels might be due to analytical variation resulting from the use of different assays. Other possible factors include differences in patient characteristics between studies, e.g. the percentage of included patients with diabetes mellitus, and predialysis blood pressure, hydration status, plasma osmolality and pain related to cannulation of the fistula. Most of the included studies, however, lack description of these factors. This precludes the use of random effect meta-analysis and meta-regression analysis to consider between-study variability and to assess factors that could explain the differences in plasma AVP levels within HD patients and between HD patients and healthy individuals, respectively.

\section{Effect of Dialysis on Plasma AVP Levels}

Thirty-seven studies, comprising 681 patients, were included in the systematic literature review. Twenty-six of these studies, comprising 496 patients, were eligible for the meta-analysis since these studies reported the mean and standard deviation of plasma AVP levels before and after standard HD. Several studies observed a significant increase in plasma AVP levels during $\operatorname{HD}[15,16,29,38$, $52,53,57]$, whereas the other studies did not [32-37, 3944, 46, 49-51, 54-56, 58]. Overall, plasma AVP levels showed little or no increase during standard HD (7.0 \pm 4.9 and $8.8 \pm 9.3 \mathrm{pg} / \mathrm{ml}$ for pre- and post-HD, respectively; $\mathrm{p}=0.433$ ). These results were confirmed by meta-analysis (mean difference $0.13 \mathrm{pg} / \mathrm{ml}, 95 \% \mathrm{CI}-0.82$ to 1.07 ; fig. 4). However, interpretation of the overall results should be done with caution, considering significant between-study heterogeneity $\left(\chi^{2}=159.05 ; \mathrm{p}<0.001 ; \mathrm{I}^{2}=84 \%\right)$. This might be explained by differences in characteristics of the included patients and differences in study design.

When a meta-regression analysis was performed, investigating whether patient characteristics (i.e. age, gender, change in blood pressure and plasma osmolality during HD) or study design (i.e. treatment duration and dialysate sodium used) were associated with the change in AVP during HD, no significant explanatory associations were found (all $\mathrm{p}>0.10$ ).

When looking into the studied patient subpopulations in more detail, plasma AVP levels did not change significantly during standard HD in the vast majority of hypotension-prone patients $[29,34,55]$ or in normotensive or hypertensive patients $[32,37,44,49,54,59]$. Other studies did not specify whether their patient populations were hypotension-prone or not, but also found no change, or even a decrease, in plasma AVP levels during HD, irrespective of whether blood pressure remained stable $[41,43,50,51$, $58]$ or decreased during $\operatorname{HD}[33,35,36,39,40,46]$.

\section{Other Dialysis Techniques}

Studies that used specific dialysis techniques, like ultrafiltration-only (UF-only) and HD with sodium profiling, may give better insight into the physiological re- 
Healthy controls

Cernaro, 2012 [24]

Zoccali, 1991 [47]

Martinez-Vea, 1985 [46]

Iitake, 1985 [37]

Nord, 1979 [25]

Hammer, 1979 [45]

Shimamoto, 1977 [35]

Dialysis patients

Cernaro, 2012 [24]

Ettema, 2012 [34]

van der Zee, 2007 [33]

Katzarski, 1999 [44]

Witkowicz, 1999 [53]

Uusimaa, 1999 [51]

Nakayama, 1998 [16]

Iimura, 1996 [57]

Friess, 1995 [29]

Grzeszczak, 1995 [52]

Hegbrant, 1994 [56]

Hegbrant, 1994 [43]

Odar-Cederlöf, 1993 [2]

Hegbrant, 1993 [59]

Hegbrant, 1993 [42]

Heintz, 1993 [55]

Yamada, 1993 [15]

Os, 1993 [40]

Graziani, 1993 [49]

Zoccali, 1991 [47]

Heidbreder, 1990 [50]

Elias, 1989 [58]

Andersson, 1988 [41]

Papadoliopoulou, 1987 [32]

Larochelle, 1987 [38]

Jawadi, 1986 [39]

Martinez-Vea, 1985 [46]

Iitake, 1985 [37]

Fasanella d'Amore, 1985 [48]

Wizemann, 1983 [54]

Horký, 1979 [36]

Nord, 1979 [25]

Hammer, 1979 [45]

Shimamoto, 1977 [35]
30

45

35

5

6

10

33

50

15

10

16

39

12

5

13

23

30

10

10

12

11

11

13

12

13

13

14

51

10

10

18

38

25

23

40

6

6

25

10

7

28

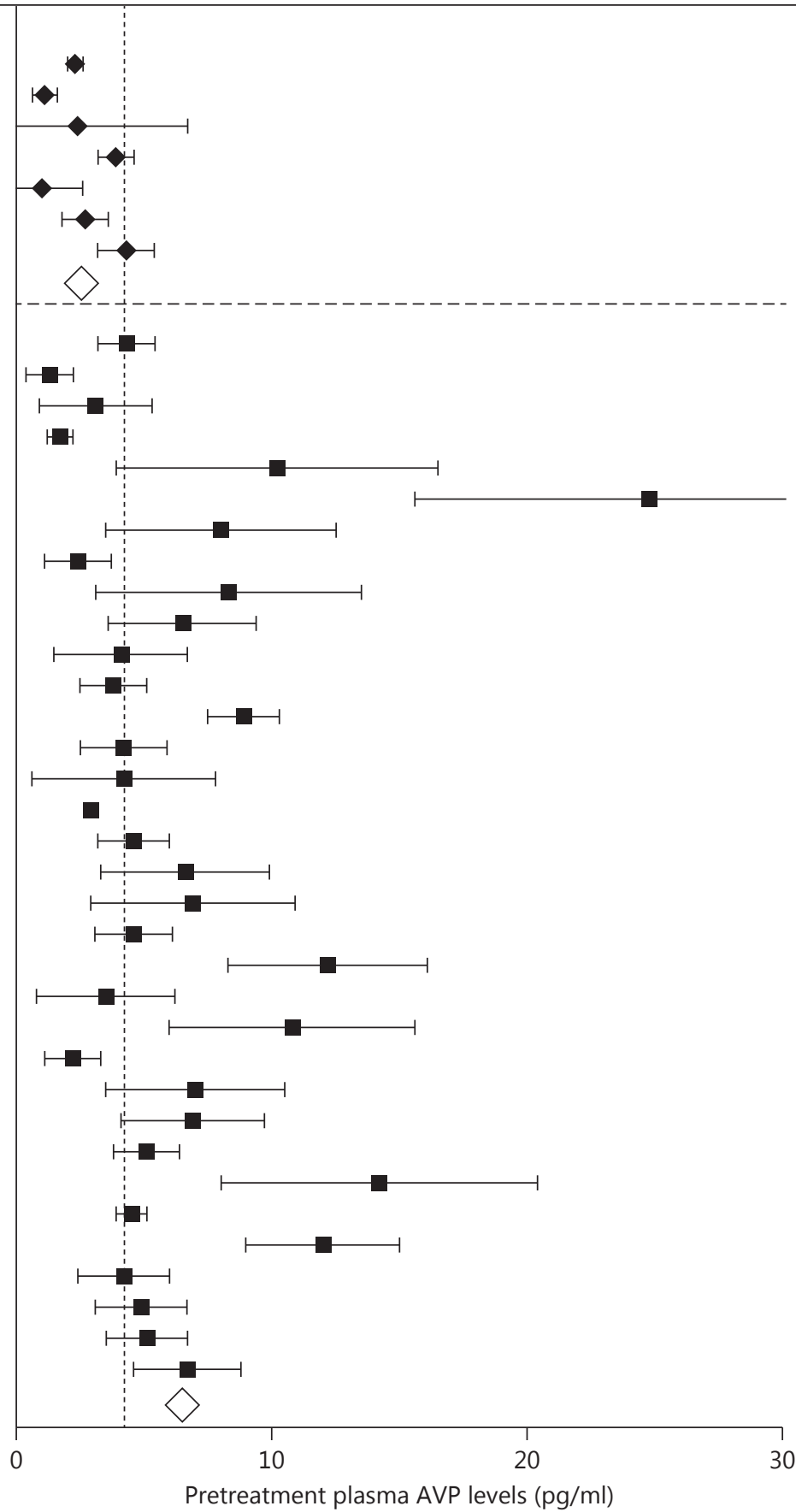

Fig. 3. a Plasma AVP levels (pg/ml) in dialysis patients pretreatment and healthy controls that were included in the same study as dialysis patients. The vertical dotted line indicates a plasma AVP level of $4 \mathrm{pg} / \mathrm{ml}$; $\diamond$ denotes mean \pm SD in healthy subjects; $\square$ denotes mean \pm SD in patients; $\diamond$ denotes mean in healthy subjects and in patients. Studies are ordered by year of publication.

(For fig. 3b, see next page.) 


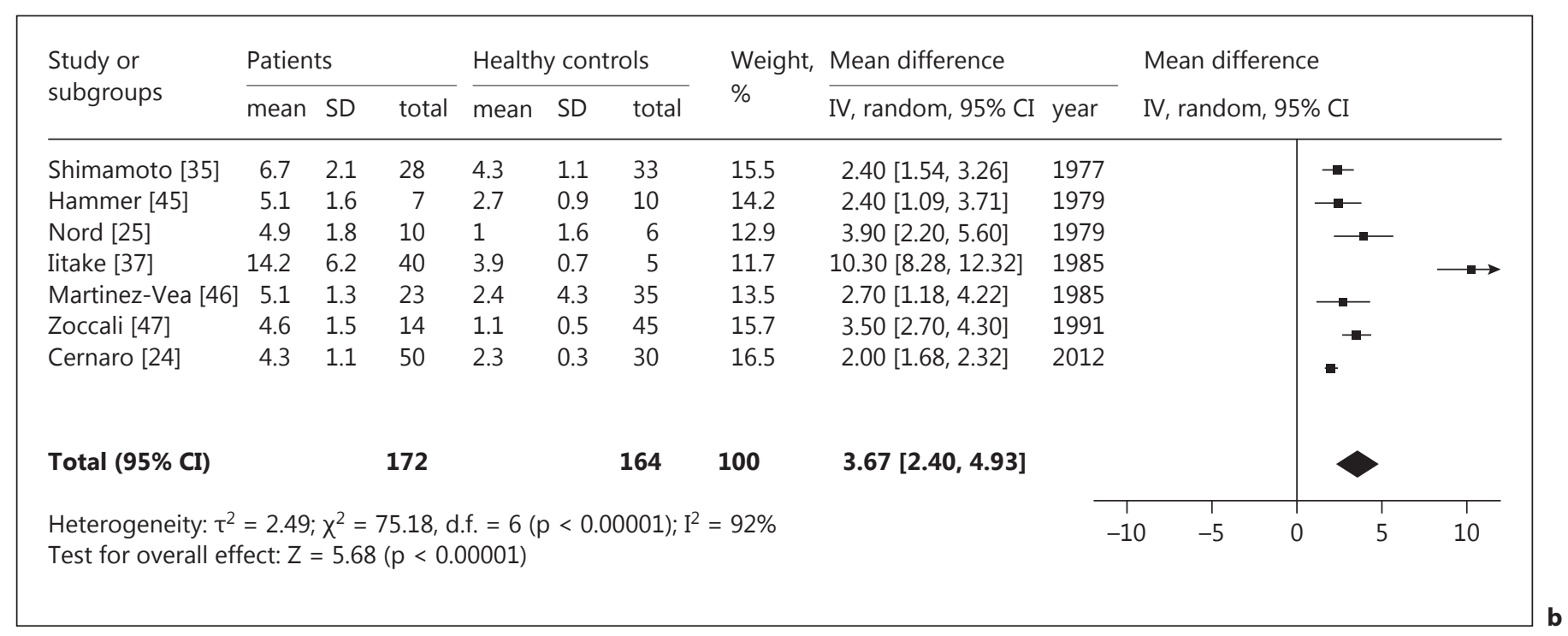

Fig. 3. b Absolute differences in AVP levels (pg/ml) between HD patients before treatment and healthy controls in studies that provided a within-study comparison of plasma AVP levels in both groups. Studies are ordered by year of publication. Mean differences are pooled using the random-effects model and shown on a scale from -10 to $10 \mathrm{pg} / \mathrm{ml}$. CI = Confidence interval; IV = inverse variance.

sponse of AVP to various aspects of the dialysis treatment since the volumetric and osmotic stimuli of AVP release can be (more or less) studied in isolation. Four studies used UF-only. The course of plasma AVP levels in response to the course of blood pressure in these studies appeared to be in line with the physiological expectation: a stable blood pressure was associated with unchanged AVP levels $[45,58]$ while a decrease in blood pressure was accompanied by increases in plasma AVP levels [46, 47].

Studies in which UF-only was preceded or followed by isovolumic HD showed divergent results regarding the course of AVP [2, 39, 40, 48, 59]. It is beyond the scope of this article to discuss these studies in detail. Studies in which HD with intermittent ultrafiltration was applied showed that mean plasma AVP levels changed in the opposite direction to changes in blood volume $[31,60]$, although plasma AVP levels did not closely follow changes in blood volume in the individual patient [60].

One group investigated plasma AVP level responses to HD with varying dialysate sodium concentrations and varying ultrafiltration rates during multiple treatment sessions. Again, inconsistent results were found [25]. One study investigated the effect of the biofeedback system Hemocontrol on AVP levels. This technique continuously varies dialysate sodium concentrations and ultrafiltra- tion rates in response to the patient's relative blood volume level [61, 62]. An initial increase in plasma osmolality and a prominent fall in blood volume coincided with higher plasma AVP levels during the first hour of Hemocontrol treatment in comparison with standard HD [34]. However, AVP levels did not differ between standard HD and Hemocontrol HD at the end of the treatment.

Finally, two studies looked into plasma AVP levels during hemodiafiltration, also with mixed results. Blood pressure and plasma osmolality decreased in both studies, while plasma AVP levels decreased in one study [24] and rose in another study [54].

\section{Plasma Vasopressin and Intradialytic Hypotension}

Some studies suggested a possible role for deficient or inadequate AVP increase during HD in the pathogenesis of intradialytic hypotension [16, 24, 33]. Eight studies investigated plasma AVP levels in relation to intradialytic hypotension. These studies showed mixed results, but it is important to note that plasma AVP levels were generally measured after intradialytic hypotension instead of during intradialytic hypotension. In addition, in these eight studies a total of five different definitions of intradialytic hypotension were used $[21,29,34,47,60]$, where- 


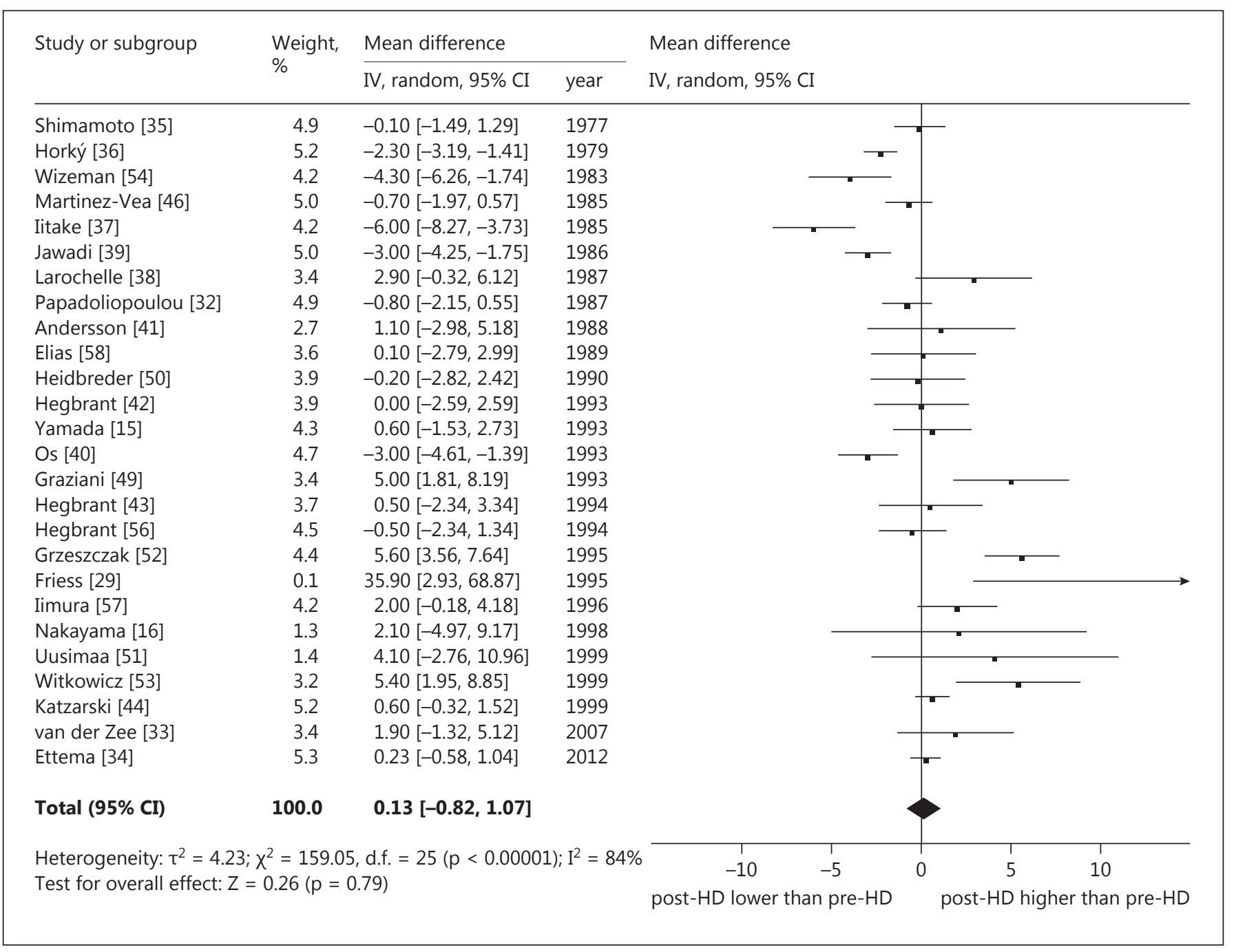

Fig. 4. Absolute changes in plasma AVP (pg/ml) levels from pre- to post-HD. Studies are ordered by year of publication. Mean differences are pooled using the random-effects model and shown on a scale from -10 to $10 \mathrm{pg} /$ $\mathrm{ml}$. CI = Confidence interval; IV = inverse variance.

as in three studies no definition was provided at all $[2,45$, 48]. In some of these studies it was found that plasma AVP levels were higher after intradialytic hypotension had occurred $[45,48,60]$, whereas others found no difference in plasma AVP levels between patients with and without intradialytic hypotension [47], or only observed higher AVP levels when intradialytic hypotension was accompanied by nausea [29].

In only two studies was blood sampling performed at the moment that intradialytic hypotension actually occurred [21, 29]. In one of these studies, Rho et al. [21] showed that plasma AVP levels did not differ between patients who did and those who did not experience intra- dialytic hypotension. All in all, at present no clear conclusion can be made about whether an inadequate rise in AVP levels has a role in the pathophysiology of intradialytic hypotension.

\section{Potential Mechanism of the Relative AVP Deficiency during HD}

Presently, there is no definite answer to why AVP levels do not increase during HD despite significant decreases in blood volume and blood pressure. However, several mechanisms can be considered. 
First, since AVP secretion is under control of the baroreflex arc, autonomic dysfunction could impair the release of AVP, as has been suggested by several groups [21, 24, 33]. Dysfunction of the autonomic nervous system is common in patients on $\operatorname{HD}[47,63,64]$. However, literature on AVP kinetics in relation to autonomic impairment in HD patients is scarce and conflicting. One group suggested that a defect in the afferent limb of the baroreceptor reflex arc might be responsible for inadequate AVP stimulation in some patients with recurrent intradialytic hypotension [29] whereas another group concluded that the reflex AVP secretion was unaffected in patients on $\mathrm{HD}$, even in the presence of autonomic dysfunction [47].

Second, it has been suggested that an increase in the production of nitric oxide during HD might impair AVP release [33]. Animal studies indeed suggest an inhibitory effect of nitric oxide on AVP release [65, 66]. However, this concerns a relation at the hypothalamic-pituitary level. To our knowledge, it has not been studied whether peripherally released nitric oxide is also able to inhibit AVP release from the pituitary gland. Nitric oxide, however, may inhibit sympathetic activity in patients experiencing intradialytic hypotension [67] and, consequently, could attenuate AVP secretion.

Third, it has been suggested that increases in plasma AVP levels may be inadequate due to removal of AVP by $\mathrm{HD}$, considering its molecular size of only $1 \mathrm{kDa}$ [68]. At present, however, no clear conclusion can be drawn on whether AVP is removed in substantial amounts by HD. One study has reported similar plasma AVP concentrations in the in- and outgoing blood before and after the dialyzer during HD [69], suggesting that there is no significant clearance of AVP, whereas two other studies detected AVP in the ultrafiltrate [37, 70], suggesting that there is at least some removal of AVP by HD. Systematic data on AVP clearance by dialyzers are lacking.

\section{Effect of Administration of Exogenous AVP on Hemodynamic Stability during HD}

Four groups have investigated the effect of administration of AVP or synthetic AVP analogues on hemodynamic stability during HD [33, 71-73] (online suppl. table S3). Studies using the AVP analogues lysine vasopressin and desmopressin intranasally in hypotension-prone patients demonstrated that the incidence of intradialytic hypotension (defined as a decrease in systolic blood pressure $>10$ $\mathrm{mm} \mathrm{Hg}$ [71] and a decrease in MAP to $<70 \mathrm{~mm} \mathrm{Hg}$ after treatment initiation [73]) decreased significantly in com-

Dialysis Hypotension and Vasopressin parison with placebo $[71,73]$. In addition, the total volume of intravenous fluid administration was significantly lower with lysine vasopressin compared with placebo [73] and post-HD blood pressure was higher when desmopressin was used before HD compared with placebo [71]. When AVP was administered intravenously, an association between an improved intradialytic blood pressure stability [33] and a significantly increased intradialytic blood pressure [72] were found.

Currently available AVP analogues for clinical practice are desmopressin and terlipressin. Terlipressin is a nonselective AVP analogue and it has a slightly greater affinity for V1 receptors than AVP [20]. Since terlipressin predominantly has vasoconstrictive effects, this drug may be preferable for the prevention of intradialytic hypotension over desmopressin, which exerts mainly antidiuretic actions. Terlipressin itself is inactive and is gradually converted into the active metabolite lysine vasopressin, with an effect half-life of $6 \mathrm{~h}[19,20]$ and a peak concentration after 60 $120 \mathrm{~min}$. Administration of vasopressin to generate a plasma concentration of $20-30 \mathrm{pg} / \mathrm{ml}$ was found to produce a pressor response with minimal organ hypoperfusion in patients without renal disease [19]. Before exogenous AVP administration is applicable in routine clinical practice, optimal timing and dosage of AVP analogues and the safety of their repetitive administration should be determined.

\section{Knowledge Gaps and Future Research}

Although our systematic review provides insight into the potential role of vasopressin in intradialytic hypotension, a number of questions remain. First, it is uncertain whether post-HD AVP levels are a good representation of the intradialytic course of AVP. Future studies should, therefore, investigate plasma AVP levels during HD in relation to pre- and postdialysis levels. Second, it should be investigated whether AVP is removed by the artificial kidney during HD. Third, a firm conclusion on the relationship between AVP levels and intradialytic hypotension is hampered by the use of varying definitions of intradialytic hypotension $[21,29,34,47,60]$. Future studies should therefore use a uniform definition of intradialytic hypotension, such as the one provided by the European Best Practice Guidelines [74]. However, the data from intervention studies showing that exogenous AVP administration results in improved hemodynamic stability indirectly supports the belief that the lack of a rise of AVP could be pathophysiologically involved in the development of intradialytic hypotension. 


\section{Conclusions}

This systematic literature review shows that plasma AVP levels are higher in dialysis patients compared with healthy individuals, but do not rise during HD despite decreases in blood pressure and blood volume, which are physiological stimuli for AVP secretion. Potential underlying mechanisms for the lack of an increase in AVP levels during dialysis include dysfunction of (components of) the baroreceptor arc, an inhibitory effect of nitric ox- ide on the sympathetic nervous system and removal by dialysis. The lack of a rise in AVP levels during HD may play a role in the onset of intradialytic hypotension and administration of AVP or an AVP analogue might benefit HD patients.

\section{Disclosure Statement}

There are no conflicts of interest to declare.

\section{References}

1 Daugirdas JT: Pathophysiology of dialysis hypotension: an update. Am J Kidney Dis 2001; 38:S11-S17.

2 Odar-Cederlóf I, Theodorsson E, Eriksson CG, Hamberger B, Tidgren B, Kjellstrand CM: Vasoactive agents and blood pressure regulation in sequential ultrafiltration and hemodialysis. Int J Artif Organs 1993;16:662-669.

-3 Schreiber MJ Jr: Setting the stage. Am J Kidney Dis 2001;38:S1-S10.

4 Shoji T, Tsubakihara Y, Fujii M, Imai E: Hemodialysis-associated hypotension as an independent risk factor for two-year mortality in hemodialysis patients. Kidney Int 2004;66: 1212-1220.

$\checkmark 5$ Santoro A, Mancini E, Basile C, Amoroso L, Di Giulio S, Usberti M, Colasanti G, Verzetti G, Rocco A, Imbasciati E, Panzetta G, Bolzani R, Grandi F, Polacchini M: Blood volume controlled hemodialysis in hypotension-prone patients: a randomized, multicenter controlled trial. Kidney Int 2002;62:1034-1045.

-6 Franssen CF, Dasselaar JJ, Sytsma P, Burgerhof JG, de Jong PE, Huisman RM: Automatic feedback control of relative blood volume changes during hemodialysis improves blood pressure stability during and after dialysis. Hemodial Int 2005;9:383-392.

-7 Dasselaar JJ, Huisman RM, de Jong PE, Franssen CF: Measurement of relative blood volume changes during haemodialysis: merits and limitations. Nephrol Dial Transplant 2005;20:2043-2049.

8 Boero R, Pignataro A, Ferro M, Quarello F: Sympathetic nervous system and chronic renal failure. Clin Exp Hypertens 2001;23:69-75.

-9 Ligtenberg G: Regulation of blood pressure in chronic renal failure: determinants of hypertension and dialysis-related hypotension. Neth J Med 1999;55:13-18.

10 Kokot F, Grzeszczak W, Zukowska-Szczechowska E, Wiecek A: Water immersion induced alterations of plasma vasopressin levels and activity of the renin-angiotensin-aldosterone system in noninflammatory acute renal failure and end-stage renal failure. Int Urol Nephrol 1990;22:285-293.

11 Raizada V, Hillerson D, Amaram JS, Skipper B: Angiotensin II-mediated left ventricular abnormalities in chronic kidney disease. J Investig Med 2012;60:785-791

12 Blankestijn PJ, London G, Fliser D, et al: Major pathways of the reno-cardiovascular link: the sympathetic and renin-angiotensin systems. Kidney Int Suppl 2011;1:13-16.

13 Bayya A, Rubinger D, Linton DM, Sviri S: Evaluation of intradialytic hypotension using impedance cardiography. Int Urol Nephrol 2011;43:855-864.

14 Straver B, Roggekamp MC, de Vries PM, ter Wee PM: Systemic vascular resistance in intradialytic hypotension determined by means of impedance cardiography. Blood Purif 1998; 16:281-289.

15 Yamada K, Nakayama M, Miura Y, Nakano $\mathrm{H}$, Mimura N, Yoshida S: Role of AVP in the regulation of vascular tonus and blood pressure in patients with chronic renal failure. Regul Pept 1993;45:91-95.

16 Nakayama M, Yamada K, Nakano H, Miura Y, Tuchida H, Kawaguchi Y: Stimulated secretion of arginine vasopressin during hemodialysis in patients with hemodialysis hypotension. Nephron 1998;79:488-489.

17 Goldsmith SR: Vasopressin as vasopressor. Am J Med 1987;82:1213-1219.

18 Cowley AW, Michalkiewicz M: Vasopressin and neuropeptide Y; in Izzo J, Sica D, Black H (eds): Hypertension Primer: The Essentials of High Blood Pressure, ed 4. Philadelphia, Lippincott Williams and Wilkins; 2003, pp 37-39.

19 Kam PC, Williams S, Yoong FF: Vasopressin and terlipressin: pharmacology and its clinical relevance. Anaesthesia 2004;59:993-1001.

20 Mutlu GM, Factor P: Role of vasopressin in the management of septic shock. Intensive Care Med 2004;30:1276-1291.

21 Rho M, Perazella MA, Parikh CR, Peixoto AJ, Brewster UC: Serum vasopressin response in patients with intradialytic hypotension: a pilot study. Clin J Am Soc Nephrol 2008;3:729-735.

22 Holmes CL, Patel BM, Russell JA, Walley KR: Physiology of vasopressin relevant to management of septic shock. Chest 2001;120:989-1002.

23 Barrett LK, Singer M, Clapp LH: Vasopressin: mechanisms of action on the vasculature in health and in septic shock. Crit Care Med 2007;35:33-40.
24 Cernaro V, Lacquaniti A, Lorenzano G, Loddo S, Romeo A, Donato V, Lupica R, Buemi A, Buemi M: Apelin, plasmatic osmolality and hypotension in dialyzed patients. Blood Purif 2012;33:317-323

25 Nord E, Danovitch GM: Vasopressin response in haemodialysis patients. Proc Eur Dial Transplant Assoc 1979;16:238-243.

26 Sharman A, Low J: Vasopressin and its role in critical care. Contin Educ Anaesth Crit Care Pain 2008;8:134-137.

27 Bronicki R, Checchia PA: Vasoactive agents; in Slonim AD, Pollack MM (eds.): Pediatric Critical Care Medicine, ed 1. Philadelphia, Lippincott Williams \& Wilkins, 2006, pp 664-668.

28 Holmes CL, Landry DW, Granton JT: Science review: vasopressin and the cardiovascular system part 1 - receptor physiology. Crit Care 2003;7:427-434.

29 Friess U, Rascher W, Ritz E, Gross P: Failure of arginine-vasopressin and other pressor hormones to increase in severe recurrent dialysis hypotension. Nephrol Dial Transplant 1995; 10:1421-1427.

30 Landry DW, Levin HR, Gallant EM, Ashton RC Jr, Seo S, D'Alessandro D, Oz MC, Oliver JA: Vasopressin deficiency contributes to the vasodilation of septic shock. Circulation 1997; 95:1122-1125.

31 Mann H, Konigs F, Heintz B, Gladziwa U, Kirsten R, Stiller S: Vasoactive hormones during hemodialysis with intermittent ultrafiltration. ASAIO Trans 1990;36:M367-M369.

- 32 Papadoliopoulou-Diamandopoulou N, Papagalanis N, Gavras I, Gavras H: Vasopressin in end-stage renal disease: relationship to salt, catecholamines and renin activity. Clin Exp Hypertens A 1987;9:1197-1208.

-33 van der Zee S, Thompson A, Zimmerman R, Lin J, Huan Y, Braskett M, Sciacca RR, Landry DW, Oliver JA: Vasopressin administration facilitates fluid removal during hemodialysis. Kidney Int 2007;71:318-324.

- 34 Ettema EM, Kuipers J, Groen H, Kema IP, Westerhuis R, de Jong PE, Franssen CF: Vasopressin release is enhanced by the Hemocontrol biofeedback system and could contribute to better haemodynamic stability during haemodialysis. Nephrol Dial Transplant 2012;27:3263-3270. 
35 Shimamoto K, Watarai I, Miyahara M: A study of plasma vasopressin in patients undergoing chronic hemodialysis. J Clin Endocrinol Metab 1977;45:714-720.

-36 Horký K, Sramkova J, Lachmanova J, Tomasek R, Dvorakova J: Plasma concentration of antidiuretic hormone in patients with chronic renal insufficiency on maintenance dialysis. Horm Metab Res 1979;11:241-246.

- 37 Iitake K, Kimura T, Matsui K, Ota K, Shoji M, Inoue $\mathrm{M}$, Yoshinaga K: Effect of haemodialysis on plasma ADH levels, plasma renin activity and plasma aldosterone levels in patients with end-stage renal disease. Acta Endocrinol (Copenh) 1985;110:207-213.

- 38 Larochelle P, Beroniade V, Gutkowska J, Cusson JR, Lecrivain A, du Souich P, Cantin M, Genest J: Influence of hemodialysis on the plasma levels of the atrial natriuretic factor in chronic renal failure. Clin Invest Med 1987; 10:350-354.

- 39 Jawadi MH, Ho LS, Dipette D, Ross DL: Regulation of plasma arginine vasopressin in patients with chronic renal failure maintained on hemodialysis. Am J Nephrol 1986;6:175-181.

-40 Os I, Nordby G, Lyngdal PT, Eide I: Plasma vasopressin, catecholamines and atrial natriuretic factor during hemodialysis and sequential ultrafiltration. Scand J Urol Nephrol 1993; 27:93-99.

-41 Andersson U, Sylven C, Lindvall K, Theodorsson E, Noree LO: Cardiac function and cardiovascular hormone balance during hemodialysis with special reference to atrial natriuretic peptide. Clin Nephrol 1988;30:303-307.

-42 Hegbrant J, Thysell H, Martensson L, Ekman $\mathrm{R}$, Boberg U: Changes in plasma levels of vasoactive peptides during standard bicarbonate hemodialysis. Nephron 1993;63:303-308.

-43 Hegbrant J, Martensson L, Thysell H, Ekman $\mathrm{R}$, Boberg U: Changes in plasma levels of vasoactive substances during routine acetate and bicarbonate hemodialysis. Clin Nephrol 1994;41:106-112.

44 Katzarski KS, Randmaa I, Bergstrom J: Influence of hemodialysis on intravascular volume and vasoactive hormones. Clin Nephrol 1999; 52:304-311.

45 Hammer M, Dawids S, Sorensen MB, Christensen O, Olgaard K: Hormonal response to volume depletion in non-nephrectomised patients on regular haemodialysis. Proc Eur Dial Transplant Assoc 1979;16:252-260.

-46 Martinez-Vea A, Botey A, Montoliu I, Lopez Pedret J, Revert L: Vasopressin response in hemodialysis patients. Clin Nephrol 1985;24:316.

-47 Zoccali C, Mallamaci F, Ciccarelli M, Parlongo S, Salnitro F, Curatola A: The reflex control of vasopressin in haemodialysis patients. Nephrol Dial Transplant 1991;6:631-636.

48 Fasanella d'Amore T, Wauters JP, Waeber B, Nussberger J, Brunner HR: Response of plasma vasopressin to changes in extracellular volume and/or plasma osmolality in patients on maintenance hemodialysis. Clin Nephrol 1985;23:299-302.
49 Graziani G, Badalamenti S, Del Bo A, Marabini M, Gazzano G, Como G, Vigano E, Ambroso G, Morganti A: Abnormal hemodynamics and elevated angiotensin II plasma levels in polydipsic patients on regular hemodialysis treatment. Kidney Int 1993;44:107-114.

50 Heidbreder E, Bahner U, Hess M, Geiger H, Gotz R, Kirsten R, Rascher W, Heidland A: Regulation of thirst in end-stage kidney insufficiency. Klin Wochenschr 1990;68:11271133.

51 Uusimaa P, Huttunen K, Ruskoaho H, Linnaluoto $M$, Ikaheimo M: Neurohumoral responses to a single haemodialysis in chronic renal patients. Acta Physiol Scand 1999;165: 25-31.

52 Grzeszczak W, Sornek E, Zukowska-Szczechowska E, Mizera W, Klajnowicz J: Secretion of atrial natriuretic peptide and vasopressin during hemodialysis in patients with chronic renal failure. Pol Arch Med Wewn 1995;94:195-207.

53 Witkowicz J, Kokot F, Irzyniec T, Chudek J, Ficek R: Response of vasoactive substance to blood pressure changes during hemodialysis in uremic patients. Pol Arch Med Wewn 1999;102:763-771.

54 Wizemann V, Kramer W, Knopp G, Rawer P, Mueller K, Schutterle G: Ultrashort hemodiafiltration: efficiency and hemodynamic tolerance. Clin Nephrol 1983;19:24-30.

55 Heintz B, Reiners K, Gladziwa U, Kirsten R, Nelson K, Wieland D, Riehl J, Mann H, Sieberth HG: Response of vasoactive substances to reduction of blood volume during hemodialysis in hypotensive patients. Clin Nephrol 1993;39:198-204.

56 Hegbrant J, Martensson L, Ekman R, Nielsen $\mathrm{AL}$, Thysell H: Dialysis fluid temperature and vasoactive substances during routine hemodialysis. ASAIO J 1994;40:M678-M682.

57 Iimura O, Tabei K, Nagashima H, Asano Y: A study on regulating factors of plasma refilling during hemodialysis. Nephron 1996;74:19-25.

58 Elias AN, Vaziri ND, Pandian MR, Kaupke J: Plasma concentrations of atrial natriuretic peptide, arginine vasopressin and hormones of the renin-angiotensin system in patients with end-stage renal disease. Int J Artif Organs 1989;12:153-158.

59 Hegbrant J, Thysell H, Martensson L, Ekman $\mathrm{R}$, Boberg U: Changes in plasma levels of vasoactive peptides during sequential bicarbonate hemodialysis. Nephron 1993;63:309-313.

60 Heintz B, Konigs F, Dakshinamurty KV, Kierdorf H, Gladziwa U, Kirsten R, Nelson K, Wieland D, Riehl J, Mann H: Response of vasoactive substances to intermittent ultrafiltration in normotensive hemodialysis patients. Nephron 1993;65:266-272.

61 Ronco C, Brendolan A, Milan M, Rodeghiero MP, Zanella M, La Greca G: Impact of biofeedback-induced cardiovascular stability on hemodialysis tolerance and efficiency. Kidney Int 2000;58:800-808.
62 Basile C, Giordano R, Vernaglione L, Montanaro A, De Maio P, De Padova F, Marangi AL, Di Marco L, Santese D, Semeraro A, Ligorio VA: Efficacy and safety of haemodialysis treatment with the Hemocontrol biofeedback system: a prospective medium-term study. Nephrol Dial Transplant 2001;16:328-334.

63 Savica V, Musolino R, Di Leo R, Santoro D, Vita G, Bellinghieri G: Autonomic dysfunction in uremia. Am J Kidney Dis 2001; 38:S118-S121.

64 Nakashima Y, Fouad FM, Nakamoto S, Textor SC, Bravo EL, Tarazi RC: Localization of autonomic nervous system dysfunction in dialysis patients. Am J Nephrol 1987;7:375-381.

65 Giusti-Paiva A, Ruginsk SG, de Castro M, Elias LL, Carnio EC, Antunes-Rodrigues J: Role of nitric oxide in lipopolysaccharide-induced release of vasopressin in rats. Neurosci Lett 2003;346:21-24.

66 Yamova L, Atochin D, Glazova M, Chernigovskaya E, Huang P: Role of neuronal nitric oxide in the regulation of vasopressin expression and release in response to inhibition of catecholamine synthesis and dehydration. Neurosci Lett 2007;426:160-165.

-67 Nishimura M, Takahashi H, Maruyama K, Ohtsuka K, Nanbu A, Hara K, Yoshimura M: Enhanced production of nitric oxide may be involved in acute hypotension during maintenance hemodialysis. Am J Kidney Dis 1998; 31:809-817.

68 Santoro A: Infusing vasopressin to prevent intradialytic hypotension. Nat Clin Pract Nephrol 2007;3:362-363.

69 Vaziri ND, Skowsky R, Saiki J, Warner A: Hemodialysis studies of antidiuretic hormone. J Dial 1980;4:185-190.

70 Shimamoto K, Ando T, Nakao T, Watarai I, Miyahara M: Permeability of antidiuretic hormone and other hormones through the dialysis membrane in patients undergoing chronic hemodialysis. J Clin Endocrinol Metab 1977;45:818-820.

71 Beladi-Mousavi SS, Beladi-Mousavi M, Hayati F, Talebzadeh M: Effect of intranasal DDAVP in prevention of hypotension during hemodialysis. Nefrologia 2012;32:89-93.

72 Shimizu K, Kurosawa T, Sanjo T: Effect of hyperosmolality on vasopressin secretion in intradialytic hypotension: a mechanistic study. Am J Kidney Dis 2008;52:294-304.

73 Lindberg JS, Copley JB, Melton K, Wade CE, Abrams J, Goode D: Lysine vasopressin in the treatment of refractory hemodialysis-induced hypotension. Am J Nephrol 1990;10:269-275.

74 Kooman J, Basci A, Pizzarelli F, Canaud B, Haage P, Fouque D, Konner K, Martin-Malo A, Pedrini L, Tattersall J, Tordoir J, Vennegoor M, Wanner C, ter Wee P, Vanholder R: EBPG guideline on haemodynamic instability. Nephrol Dial Transplant 2007;22(suppl 2):ii22-ii44.

75 Guyton AC, Hall JE: Regulation of extracellular fluid osmolarity and sodium concentration; in Guyton AC, Hall JE: Textbook of Medical Physiology, ed 11. Philadelphia, Saunders, 2006. 